\title{
Selection and Precise Application of Operating Parameters of Nd: YAG and Other Laser Sources for Material Processing
}

Jayanthi ${ }^{1}$, Kumar $\mathrm{KS}^{2 *}$ and Venkatraman $\mathrm{K}^{3}$

${ }^{1}$ Jeppiaar Institute of Technology, Chennai, India

${ }^{2}$ P.T. Lee Chengalvaraya Naicker College of Engineering, Kanchipuram, India

${ }^{3}$ SCSVMV University, Kanchipuram, India

\begin{abstract}
Nd: YAG laser has been a versatile tool for variety of material processing in the modern manufacturing industries. Apart from the easy manipulation and robustness of Nd: YAG laser beam, its wavelength absorbed by wide range of materials. Therefore, the possibility of controlling and précised values for prominent operating parameters such as average peak power, average peak power density (APPD), mean power, pulse duration, pulse energy, pulse repetition rate, interaction, pulse overlap theory and its mathematical relationships were discussed for pulsed and continuous wave. Hence, the selection of satisfactory combinations of associated parameters to produce efficient and effective material processing with reduced defects.
\end{abstract}

Keywords: Nd: YAG laser; Pulsed laser; Continuous laser; Operating parameters; Material processing

\section{Introduction}

Recently, laser welding has received much attention as a promising joining technology because it encompasses high quality, precision, performance, and speed with good flexibility and low distortion. In addition, it allows robotic linkages, reduced work force, full automation, and systematization. The theoretical and experimental study of laser material processing began in 1962, Since then, the use of laser welding has grown swiftly, as the new manufacturing possibilities became better understood [1]. In comparison of Nd: YAG laser and $\mathrm{CO}_{2}$ laser, wavelength, $10.6 \mu \mathrm{m}$ in case of a $\mathrm{CO}_{2}$ laser and $1.06 \mu \mathrm{m}$ for Nd: YAG laser beam. This means a difference in absorption of the laser beam by the materials. On other hand, Nd: YAG laser beam can deliver via an optical fiber almost without loss, while transfer of a $\mathrm{CO}_{2}$ laser beam handled through an optical mirror system [2]. The other importance of Nd-YAG laser are, being more user-friendly, rigid and compact oscillator, low reflectivity to $\mathrm{cu}, \mathrm{Al}$ and their alloys [3]. In surface cleaning of Ti alloys, Nd: YAG shows domination over $\mathrm{CO}_{2}$ laser by heat conduction into the contaminant from the surface. In terms of weldability for metallic materials, the application of $\mathrm{Nd}$ : YAG laser to weld metallic materials is steadily being increased [4]. Therefore, the application of Nd: YAG laser steadily being increased; it has been widely implemented in industrial applications. However, a common problem that has been faced by the manufactures during laser material processing is, there are more parameters (a multi input and multi output process) to control of the process quality. Hence, it is necessary to understand and precise the operating parameter for the various material processing. The present paper is to discuss about the selection and précised application of the prominent operating parameters for various laser-assisted material processing using $\mathrm{Nd}$ : YAG laser.

\section{Process Parameters Governing Pulsed Nd: YAG Laser Welding}

The construction and function of Nd: YAG is same for output characteristics of the two different modes such as continuous and pulsed wave [5]. Schematic diagram of the laser power output for a series of constant energy pulses in a self-designed shape as shown in Figure 1.
Nd: YAG laser pulse parameters are defined below:

$$
\text { AveragePeakPower }\left(\mathrm{P}_{\mathrm{P}}\right)=\frac{\text { pulseenergy }(\mathrm{J})}{\text { pulseduration }(m s)}(\mathrm{W})
$$

$$
\text { Average Peak Power Density }\left(\mathrm{P}_{\mathrm{D}}\right)=\frac{\text { average peak power }(\mathrm{kW})}{\text { spot area }\left(\mathrm{mm}^{2}\right)}\left(\mathrm{W} / \mathrm{mm}^{2}\right)
$$

Mean Power $\left(\mathrm{P}_{\mathrm{M}}\right)=\{$ Pulse energy $(\mathrm{J}) \mathrm{x}$ Pulse Repetition Rate $(\mathrm{Hz})\}(\mathrm{W})$

Where $P_{p}$ is average peak power $(W), P_{D}$ is average peak power density (APPD) $\left(\mathrm{W} / \mathrm{mm}^{2}\right), \mathrm{P}_{\mathrm{M}}$ is mean power $(\mathrm{W}), \mathrm{T}_{\mathrm{P}}$ is the pulse duration $(\mathrm{mS}), \mathrm{E}_{\mathrm{p}}$ is the pulse energy (J), PRR is the pulse repetition rate $\left(\mathrm{s}^{-1}\right), \mathrm{T}_{\mathrm{F}}$ the pulse to-pulse time $(\mathrm{mS})$, and $\mathrm{C}_{\mathrm{D}}$ (duty cycle $)=\mathrm{T}_{\mathrm{P}} / \mathrm{T}_{\mathrm{F}}$.

Mathematical relationships between the pulsed laser parameters

The mathematical relationships between the pulsed laser parameters can be formulated into various equations [5]:

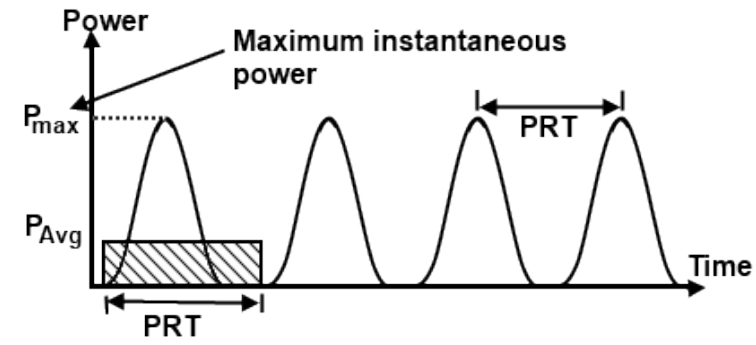

Figure 1: Schematic diagram of the input pulses in a self-designed shape.

${ }^{*}$ Corresponding author: Kumar KS, P.T. Lee Chengalvaraya Naicker College of Engineering, Kanchipuram, India, Tel: 09791451493; E-mail: lectsuresh25@gmail.com

Received August 03, 2015; Accepted August 13, 2015; Published August 23, 2015

Citation: Jayanthi A, Kumar KS, Venkatraman K (2015) Selection and Precise Application of Operating Parameters of Nd: YAG and Other Laser Sources for Material Processing. J Material Sci Eng 4: 188. doi:10.4172/2169-0022.1000188

Copyright: (c) 2015 Jayanthi A, et al. This is an open-access article distributed under the terms of the Creative Commons Attribution License, which permits unrestricted use, distribution, and reproduction in any medium, provided the original author and source are credited. 


$$
\begin{aligned}
& P_{M}=E_{P} \times P R R=\frac{E_{P}}{T_{P}} \times \frac{T_{P}}{T_{F}}(\mathrm{~W}) \\
& P_{M}=P_{P} \times C_{D}=\frac{E_{P}}{T_{P} \times D} \times D \times \frac{T_{P}}{T_{F}}(\mathrm{~W}) \\
& P_{M}=\frac{E_{P}}{T_{P} \times D} \times D \times \frac{T_{P}}{T_{F}}(\mathrm{~W}) \\
& P_{M}=P_{P} \times D \times T_{P} \times P R R \quad(\mathrm{~W})
\end{aligned}
$$

Where $D$ is a constant spot area $(\mathrm{mm}), \mathrm{P}_{\mathrm{p}}$ is the average peak power $(\mathrm{W}), \mathrm{E}_{\mathrm{P}}$ is the pulse energy $(\mathrm{J}), \mathrm{T}_{\mathrm{P}}$ is the pulse duration $(\mathrm{mS}), \mathrm{P}_{\mathrm{D}}$ is the average peak power density $\left(\mathrm{W} / \mathrm{mm}^{2}\right), \mathrm{P}_{\mathrm{M}}$ is the mean power $(\mathrm{W}), \mathrm{PRR}$ is the pulse repetition rate $(\mathrm{Hz}), \mathrm{T}_{\mathrm{F}}$ is the pulse-to-pulse time $(\mathrm{mS})$, and $\mathrm{C}_{\mathrm{D}}$ is a duty cycle.

It is observed from Eqns. (4) - (7) for a given laser power $\mathrm{P}_{\mathrm{M}}$, there are various combinations of pulsed laser parameters, which indicates both the flexibility and the complexity in the selection of pulsed laser parameters. Therefore, the satisfactory combinations of associated parameters to produce enable efficient and effective material processing with good corrosion resistance, reduced defects.

\section{Overlap theory for pulsed laser for material processing}

The cladding, alloying, welding, and cutting produced by the pulsed laser is actually by a series of overlapping. The formation and the quality of the process depend on the set-up of the various parameters. To express the mathematical relationship of the overlap theory, relevant equations are as follows [6]:

In case of welding, if the percentage of overlap, assuming onedimensional overlapping, $\mathrm{P}_{\mathrm{ER}}$, in the $\mathrm{x}$-axis direction

$$
\text { Overlap } \%, P_{E R}=\frac{\left[S-S^{\prime}\right]}{S} \times 100 \%=\left[1-\frac{S^{\prime}}{S}\right] \times 100 \%
$$

Where

$$
S^{\prime}=V \times T_{F}(\mathrm{~mm}), \quad S^{\prime}=W+V \times T_{P} \quad(\mathrm{~mm})
$$

Where, $\mathrm{V}$ is the travel speed, $\mathrm{W}$ the minor diameter of the spot weld, $S$ the major diameter of spot weld formed from a laser spot plus movement during a pulse, and $S^{\prime}$ is the length in a single spot not overlapped by successive welding spots.

Substituting the expressions for S' and S into Eqn. (8), the overlap percentage is

$$
P_{E R}=\left[1-\frac{V \times T_{F}}{W+V \times T_{P}}\right] \quad(\times 100 \%)
$$

It can understand from Eqn. (10) that overlapping depends upon the selection of pulse duration $\left(\mathrm{T}_{\mathrm{P}}\right)$, pulse-to-pulse time $\left(\mathrm{T}_{\mathrm{F}}\right)$, and traverse speed $(\mathrm{V})$ for a given mean power $\left(\mathrm{P}_{\mathrm{M}}\right)$ and spot size. For further understanding the relationship between traverse speed and overlapping, Eqn. (10) can rearranged as

$$
\frac{W}{V}=\frac{T_{F}}{\left(1-P_{E R}\right)}-T_{P}
$$

For pulsed laser applications, the constraint $0<\mathrm{P}_{\mathrm{ER}}<1$ exists, except for when $(=1)$, there is relative motion between the pulsed laser beam and the work piece. Therefore, the traverse speed for pulsed laser seam welding applications is subject to the following mathematical relationship:

$$
0<V \leq \frac{W}{T_{F}-T_{P}}
$$

\section{Parametric analysis in the pulsed laser material processing}

For material processing using pulsed laser beam, there are more main parameters than for both pulsed and continuous wave $(\mathrm{CW})$, as described below [6]:

The average peak power density $\left(\mathrm{P}_{\mathrm{D}}\right)$ for pulsed laser, which correlated directly to the average power density for spot and continuous wave welding;

$$
\frac{P_{M}}{D}=P_{D}\left(=\frac{E_{P}}{T_{P} \times D}\right) \times C_{D}\left(\mathrm{~W} / \mathrm{mm}^{2}\right)
$$

The interaction time $\left(T_{I N}\right)$ for pulsed laser with target material

$$
\mathrm{T}_{\mathrm{IN}}=\frac{\mathrm{ds}}{\mathrm{V}} \times \mathrm{C}_{\mathrm{D}}\left(=\frac{\mathrm{T}_{\mathrm{P}}}{\mathrm{T}_{\mathrm{F}}}\right)(\mathrm{mS})
$$

The specific energy $\left(E_{\text {avg }}\right)$

$$
\begin{aligned}
& E_{a v}=\frac{P_{P} \times T_{P} \times P R R}{d s \times V}=\frac{P_{P} \times C_{D}}{d s \times V}=\frac{E_{P}}{d s \times V \times T_{F}} \\
& =\frac{P_{M}}{d s \times V}=\frac{\left(P_{P} \times T_{I} N\right)}{d_{S}^{2}}=\left(\frac{\Pi}{4}\right) \times P_{D} \times T_{I N}(J)
\end{aligned}
$$

The pulse overlapping rate $\left(\mathrm{P}_{E R}\right)$

$$
\begin{aligned}
& P_{E R}=\left[1-\frac{V \times T_{F}}{W+V \times T_{P}}\right] \\
& =\left[1-\frac{1}{\left(\left(W \times d s \times E_{a v}\right) / E_{P}\right)+T_{P} / T_{F}}\right] \\
& =\left[1-\frac{1}{\left(\left(W \times d s \times E_{a v}\right) / E_{P}\right)+C_{D}}\right] \\
& =\left[1-\frac{1}{\left(\left(W \times T_{I N}\right) /\left(d s \times T_{P}\right)\right)+C_{D}}\right]
\end{aligned}
$$

Effects of pulse duration $\left(\mathrm{T}_{P}\right)$ on heat flow

In case of welding, an overall heat balance on the melt pool, assuming that all the incident energy used only in the melting of weld ingot could ideally state as follows:

$$
E_{P} \times \eta=\frac{d W\left(W+T_{P} \times V\right)}{4} \pi \times \rho \times\left(C_{P} \Delta \mathrm{T}+L_{m}\right)
$$

where $\mathrm{Z}$ is the coupling efficiency, $\mathrm{W}$ the bead width $(\mathrm{mm}), \mathrm{d}$ the weld penetration $(\mathrm{mm}), V$ the traverse speed $(\mathrm{mm} / \mathrm{s}), \rho$ the density of workpiece $\left(\mathrm{kg} / \mathrm{m}^{3}\right), \mathrm{C}_{\mathrm{p}}$ the specific heat $(\mathrm{J} / \mathrm{kg} \mathrm{K}), \Delta \mathrm{T}$ the temperature rise to cause melting $(\mathrm{K})$, and $\mathrm{L}_{\mathrm{m}}$ the latent heat of fusion $(\mathrm{J} / \mathrm{kg})$.

According to Eq. (17), the weld ingot volume $\mathrm{W} \mathrm{d}\left(\mathrm{W}+\mathrm{V} \times \mathrm{T}_{\mathrm{p}}\right) \mathrm{x}$ $\Pi / 4$ is directly proportional to " $W$ " as " $\mathrm{d}$ " is constant and $V \times T_{p}<<$. Thus, the entire trend of the heat flow increasing with the average peak power density $\left(\mathrm{P}_{\mathrm{D}}\right)$ and the pulse duration $\left(\mathrm{T}_{\mathrm{P}}\right)$ can be justified.

\section{Selection of Laser Output Mode for Compatibility of Materials Processing}

Selection of suitable output mode (pulsed or continuous wave 
Citation: Jayanthi A, Kumar KS, Venkatraman K (2015) Selection and Precise Application of Operating Parameters of Nd: YAG and Other Laser Sources for Material Processing. J Material Sci Eng 4: 188. doi:10.4172/2169-0022.1000188

$(\mathrm{CW}))$ for compatibility in laser material processing are given as follows [7]:

\section{Minimum heat input}

Pulsed Nd: YAG laser is the choice. wherever the components have metallurgical constraints on heat input or there are heat-sensitive components nearby such as glass-to-metal seals or O-rings, the pulsed YAG can be set up to achieve the required processing rate at a heat input low enough not to damage the components.

\section{Speed}

Whether cutting or welding, CW Nd: YAG laser is the best choice by processing the component with a $\mathrm{CW}$ beam there is no need to overlap pulses or to re-establish the keyhole. Simply adjust power and speed along with the focus spot size to achieve the desired penetration.

\section{Welding reflective materials}

Joining of low absorption and high reflectivity such as copper and precious metals is usually pulsed Nd: YAG laser, because that has the peak power to break down the reflectivity. Hence, pulsed Nd: YAG lasers is the best choice whereas high average power required for $\mathrm{CW}$ Nd: YAG lasers.

\section{Heat treating/cladding}

Usually CW Nd: YAG lasers are preferred due to its high average power tends to be the limit to speed, case depth, or remelt thickness. Pulsed Nd: YAG lasers can do the job but their lower average power ratings rule them out except for small devices.

\section{Spot welding}

Proper selection pulse parameters Nd: YAG pulsed lasers used for the fastest and most repeatable spot weld. However, if large diameter pieces were required, CW laser will be considered.

\section{Low penetration welding}

CW laser will weld very quickly and produce parts with high throughput. Pulsed lasers might have sufficient speed also and have the benefit of dealing with material changes or spot welding requirements.

\section{Welding crack-sensitive alloys}

CW Nd: YAG laser is the best choice unless there are other constraints such as heat input. The slower cooling rate of the CW laser usually reduces cracking tendencies in steel alloys containing sulphur, phosphorus, lead, and/or selenium.

\section{Conclusion}

Nd: YAG laser has been a versatile tool for variety of material processing in the modern manufacturing due to its wavelength absorbed by wide range of materials. Therefore, the possibility of controlling prominent operating parameters of pulsed and continuous waves such as average peak power $\left(\mathrm{P}_{\mathrm{P}}\right)$, average peak power density $\left(\mathrm{P}_{\mathrm{D}}\right)$, mean power $\left(\mathrm{P}_{\mathrm{M}}\right)$, pulse duration $\left(\mathrm{T}_{\mathrm{P}}\right)$, pulse energy $\left(\mathrm{E}_{\mathrm{P}}\right)$, pulse repetition rate, interaction time, pulse overlap theory and its mathematical relationships were discussed. Hence, the selection of suitable combinations of associated parameters helps us to produce efficient and controlled material processing with reduced defects.

\section{References}

1. Sabbaghzadeh J, Azizi M, Torkamany MJ (2008) Numerical and experimental investigation of seam welding with a pulsed laser. Optics and Laser Technology 40: 289- 296.

2. Cao X, Jahazi M, Immarigeon JP, Wallace W (2006) A review of laser welding techniques for magnesium alloys. Journal of Materials Processing Technology 171: 188-204.

3. Dubey AK, Yadava V (2008) Laser beam machining - A review. Internationa journal of machine tools and manufacture 48: 609-628.

4. Nishimura S, Katsura R, Saito Y, Kono W, Takahashi H, et al. (1998) YAG welding of neutron irradiated stainless steels. Journal of Nuclear Materials 258263.

5. Tzeng YF (2000) Effects of operating parameters on surface quality for the pulsed laser welding of zinc-coated steel. Journal of Materials Processing Technology 100: 163-170.

6. Tzeng YF (2000) Parametric analysis of the pulsed Nd: YAG laser seamwelding process. Journal of Materials Processing Technology 102: 40-47.

7. Ahmed N (2005) New developments in advanced welding. CRC Press Boca Raton Boston New York Washington, DC. 